\title{
PhD and master theses on games and education: a review of the Portuguese literature
}

\author{
A. Martins, L. Oliveira \\ University of Minho, Institute of Education (PORTUGAL) \\ anarutecreal@gmail.com, lia@ie.uminho.pt
}

\begin{abstract}
The main goals of this study were the following: 1. to identify the doctoral and master theses developed in Portugal within the area of games and education; 2. to categorize the selected theses using the game-based teaching and learning (GBTL) frames purposed by Holmes and Gee (2016).

The data was retrieved through the RENATES platform, a database from the Portuguese General Direction of Statistics of Education and Science (DGEEC) that collects official information on doctoral and master dissertations held in Portugal. All dissertations, from educational sciences' courses, concluded in the last 5 years, including the words game(s) or videogame(s) in the title, were collected for analysis. Title, abstract and keywords were examined in order to categorize each thesis as studying one of the following GBTL approaches: action, structuring, bridging and/or design.

The results showed that the most common category of GBTL researched in doctoral and master theses in Portugal is, by far, the action frame, while the least studied is the design frame. It also revealed there is only a very small number of doctoral theses studying games and education in Portugal. Lastly, the study highlights the need to increase efforts to guarantee that all relevant information about PhD and Master Theses is registered on the Portuguese institutional repositories.
\end{abstract}

Keywords: game-based teaching and learning, master thesis, doctoral thesis, Portugal

\section{INTRODUCTION}

The use of games in education is a field mined with a diversity, and sometimes confusion, of practices and approaches. A field where is tough to conduct standardized research that produces incontestable results, and that faces several barriers to its implementation inside educational systems. Despite all the hustle involved, the interest in the use of games as tools to teach and learn continues to grow.

While that holds true internationally, it is important to understand what is happening locally. An interesting way to measure the attention this knowledge area is gaining at a national level is to understand the research that is being conducted by postgraduate students. Master students are at a stage where they are both being taught about, and researching, trending subjects, while doctoral students are pursuing innovative subjects or approaches with more time and more in-depth. Together they are being shaped by, and contributing to shape, the tendencies of research inside higher education institutions.

Recently there has been a new effort to comprehend, distinguish and organize the different practices within game-based teaching and learning (GBTL), with Holmes and Gee's framework of analysis [1]. The authors propose four frames to categorize GBTL: action frame, structuring frame, bridging frame and design frame.

The action frame focus on the game, with "the use of games as objects of study, either by careful analysis of the game" (to understand its features and meaning) or "through gameplay activities" (to gain a more experiential understanding) [1]. The structuring frame focus on the instructional activities, with "the use of games or game-like features to create and organize a learning environment" (or activity) [1]. The bridging frame focus on the relationships, with "the use of games or game-like features to initiate or strengthen connections amongst people, experiences, institutions or programs" [1]. Lastly, the design frame focus on the creation process, with "the use of games to promote the learner to a designer of games and game-related artefacts and experiences" [1]. 
Although the author's work is born out of the higher-education scene, the suggested frames can be used as lenses to analyse GBTL practices and strategies within different stages and contexts of education.

This study analyses the doctoral and master theses concluded in Portugal in the last 5 years (from 2013 to 2017) in Educational Sciences, and categorises each of the GBTL strategies researched, using Holmes and Gee's framework [1].

\section{METHODOLOGY}

The data was retrieved through the RENATES platform, a database from the Portuguese General Direction of Statistics of Education and Science (DGEEC - Direção-Geral de Estatísticas da Educação e Ciência), that collects official information on doctoral theses and master's dissertations held in Portugal [2,3]. All theses that included the words "game(s)" or "videogame(s)" in the title were collected for analysis. From those, the theses from educational sciences' courses, concluded between 2013 and 2017, were selected for further classification, in a total of 4 doctoral theses and 154 master theses.

Theses that were not available in the RCAAP portal were excluded. RCAAP portal, an initiative from UMIC Knowledge Society Agency, developed by FCCN Fundação para a Computação Científica Nacional, with the technical and scientific collaboration from Minho University, aims to collect, aggregate and index Open Access scientific contents from Portuguese institutional repositories. The decision to exclude those dissertations was due to the lack of access to all the information required to conduct a rigorous analysis.

The title, abstract and keywords were then examined in order to categorize each thesis as studying one of the following game-based teaching and learning approaches: action frame, structuring frame, bridging frame and design frame.

\section{RESULTS}

The results show the number of theses retrieved from the RENATES platform, registered in the RCAAP portal, and pertinent for this study, by student degree (doctoral and master) and by gamebased teaching and learning category.

\subsection{PhD Theses}

Only four doctoral theses, with the word game(s) or videogame(s) were concluded during the past 5 years in Portugal. One thesis was excluded for being out the relevant scope (i.e. the use of GBTL strategies). Two dissertations studied GBTL within an Action Frame. One dissertation didn't fit any of the four proposed categories.

\subsection{Master Theses}

154 master theses, from educational sciences' courses and with the words game(s) or videogame(s) in the title, were concluded during the past 5 years in Portugal. Only 113 of those were registered in the Open Access National Repository RCAAP.

18 dissertations were excluded for being out of the relevant scope (i.e. the use of GBTL strategies).

All other theses, in a total of 95, were analysed and categorized as being within one of the four frames proposed by Holmes and Gee [1]. There were cases where a thesis could fit into more than one category, and cases where it didn't fit any.

Table 1 presents the results, showing the percentage of master theses by GBTL category. 
Table 1. Percentage of Master Theses by GBTL category

\begin{tabular}{c|c}
\hline Frame & Percentage \\
\hline Action & 74,7 \\
\hline Structuring & 8,4 \\
\hline Bridging & 3,2 \\
\hline Design & 2,1 \\
\hline Action + Structuring & 2,1 \\
\hline Action + Bridging & 3,2 \\
\hline Action + Design & 1,1 \\
\hline None of the frames & 5,3 \\
\hline \hline
\end{tabular}

\section{CONCLUSIONS}

This paper intends to contribute to a better understanding of the research conducted by Portuguese doctoral and master students within the area of games and education, in order to grasp the amount of effort that has been devoted to this area, and identify what are the most common approaches to the use of games in education in Portugal. There are four main take-away conclusions from this study, which are highlighted below.

First of all, it reveals that there is a very small number of doctoral theses, within educational sciences' courses, studying games, in Portugal. The reasons behind this should be further investigated.

Second, the Action Frame is the most researched strategy in GBTL, and the only one gaining attention from PhD projects. This strategy uses games in education to "demonstrate an idea or principle", "help students experience some concept or event", "become a "touchstone» for discussions around complex ideas" or "study the game as a kind of "textual» artefact" [1]. The fact that this is the most researched GBTL frame is probably because it is also the GBTL strategy most used in Portugal, but further work needs to be done to confirm this hypothesis.

The Design Frame is the least researched strategy in GBTL. This strategy uses game design to "introduce students to basic programming concepts", "promote "design literacy» or "design thinking»", "enhance students' understanding of disciplinary concepts and ideas", "educate teachers about how to incorporate GBTL into their classes", or "promote systems thinking" [1]. The fact that this is the least researched GBTL frame is probably because it is a strategy narrowly used in Portugal yet. Again, further work needs to be done to confirm this hypothesis.

Third, $27 \%$ of the theses pertinent to this study are not registered on the Portuguese institutional repositories. This makes it hard to conduct exhaustive research on the scientific production of Doctoral and Master Students in Portugal. The present study emphasis the need to increase efforts to guarantee that all significant information is easily accessible. In addition, a small set of thesis, though having the words game(s) or videogame(s) in the title, and being labelled as from educational sciences' courses, fall out of the scope of GBTL strategies.

Forth, some theses didn't fit into any of the four categories proposed by Holmes and Gee [1], leaving space to create a fifth category, something envisioned for future work as well. 


\section{ACKNOWLEDGEMENTS}

This article reports research developed within the PhD Program Technology Enhanced Learning and Societal Challenges, funded by Fundação para a Ciência e Tecnologia, FCT I. P. - Portugal, under the contract PD/BD/127783/2016. This work is also funded by CIEd - Research Centre in Education, Institute of Education, University of Minho, through national funds of FCT/MCTES-PT.

The authors would like to thank Professor José Caldeira Duarte for his advice and expertise.

\section{REFERENCES}

[1] J. B. Holmes, E. R. Gee, "A framework for understanding game-based teaching and learning", On the Horizon, Vol. 24 Issue: 1, pp.1-16, 2016.

[2] RENATES - National Register of Theses and Dissertations, 2017. Retrieved from https://renates.dgeec.mec.pt/

[3] J. M. Moreira, J. Carvalho, R. Saraiva, E. Rodrigues, "Repositório Científico de Acesso Aberto de Portugal: uma ferramenta ao serviço da ciência portuguesa", Congresso Nacional de Bibliotecários, Arquivistas e Documentalistas, Políticas de informação na sociedade em rede: actas", APBAD, ISBN 978-972-9067-39-6, 2010.

[4] RCAAP portal, 2017. Retrieved from https://www.rcaap.pt/ 